\title{
Adherence and Infectivity of Green Fluorescent Protein-Labeled Pseudomonas plecoglossicida to Ayu Plecoglossus altivelis
}

\author{
Sukenda ${ }^{1,2}$ and Hisatsugu Wakabayashi ${ }^{1,3 *}$ \\ ${ }^{1}$ Department of Aquatic Bioscience, Graduate School of Agricultural and Life Sciences, \\ The University of Tokyo, Yayoi 1-1-1, Bunkyo, Tokyo 113-8657, Japan \\ ${ }^{2}$ Department of Aquaculture, Faculty of Fisheries and Marine Sciences, \\ Bogor Agricultural University, Bogor 16680, Indonesia \\ ${ }^{3}$ HW Fish Health Laboratory, Sendagi 3-22-11-717, Bunkyo, \\ Tokyo 113-0022, Japan
}

(Received March 21, 2001)

\begin{abstract}
We report green fluorescent protein (GFP) as a useful reporter molecule to track the occurrence of Pseudomonas plecoglossicida in ayu Plecoglossue altivelis. The gfp gene was placed in a shuttle vector pME4510 and then three kinds of GFP vectors, pSKL01, pSKT03 and pSKN04 were constructed, in which lac, tac, and neophosphotransferase II (npt2) promoters drove the expression of GFP, respectively. A promoterless GFP vector was designated as pSKP02. $P$. plecoglossicida carrying pSKT03 gave the highest expression of GFP. In addition, pSKT03 was relatively stable under non-selective pressure and there was no significant changes in the in vitro growth and pathogenicity of the cells carrying this plasmid. The cells of fluorescent $P$. plecoglossicida attaching to the body surface of ayu were easily detected under a fluorescence microscope. It was revealed that they adhered predominantly to the microscopic injuries in the skin and fins.
\end{abstract}

Key words: Pseudomonas plecoglossicida, green fluorescent protein, Plecoglossus altivelis, adherence, ayu

Pseudomonas plecoglossicida is a pathogen causing bacterial hemorrhagic ascites (BHA) in ayu (Plecoglossus altivelis) in Japan (Wakabayashi et al., 1996; Nishimori et al., 2000). Sukenda and Wakabayashi $(1999,2000)$ described the kinetics of this bacterium in the experimentally infected fish based on the microbiological culture and real-time quantitative polymerase chain reaction. To study the infection process of this disease, it was apparent that many aspects could be investigated more easily if a visible marker could be introduced into the bacterial cells.

Recently, the gfp gene encoding green fluorescent protein (GFP) from a jellyfish (Aequorea victoria) was shown to be expressed in both eukaryotic and prokaryotic cells (Chalfie et al., 1994). GFP is a monomeric 238 amino-acid protein that emits green light when excited with blue light. The usefulness of GFP in tag-

\footnotetext{
* Corresponding author

E-mail: hisa718@alpha.ocn.ne.jp
}

ging a pathogenic bacterium of fish has been illustrated by Ling et al. (2000). Edwardsiella tarda was tagged with Escherichia coli vector (pGFPuv) and the infection kinetic of the bacterium was studied in vitro and in vivo. However, the current lack of constructs for diverse groups of bacteria make these systems inapplicable for other bacteria as the pGFPuv could not be expressed in $P$. plecoglossicida.

Previous experiments show that immersion challenge is considered as a suitable challenge model in reproducing $\mathrm{BHA}$ which resembles a natural infection (Sukenda and Wakabayashi, 1999; 2000). Moreover, the skin is likely the main portal of entry for $P$. plecoglossicida, since the bacterium was found in early stages post-infection (Sukenda and Wakabayashi, 2000). Many authors have noted that injures are among the main sites of bacterial adherence on the skin and fins of fish (Schneider and Nicholson, 1980; CrouseEisnor et al., 1985; Ventura and Grizzle, 1987; Speare and Mirsalimi, 1992). However, the precise mechanism 
of their adherence to the body surface of fish is as yet unknown. We used GFP as a molecular marker for $P$. plecoglossicida to study the adherence sites of $P$. plecoglossicida in the body surface of ayu. Its adherence was also compared with non-pathogenic Escherichia coli as well as microspheres.

\section{Materials and Methods}

Bacterial strain, plasmids, media and culture conditions

The bacterial strains and plasmids used in this study are listed in Table 1. E. coli JM109 and $P$. plecoglossicida FPC $951^{\top}$ (= ATCC $\left.700383^{\top}\right)$ carrying GFP constructs were grown in LB medium containing gentamicin $(15 \mu \mathrm{g} /$ $\mathrm{mL}$ ) at $37^{\circ} \mathrm{C}$ and $25^{\circ} \mathrm{C}$, respectively.

\section{DNA cloning and polymerase chain reaction (PCR)}

Plasmid extraction, restriction enzyme, PCR products purification, agarose gel electrophoresis, gel-isolated DNA fragment purification, dephosphorylation and ligation were carried out using standard methods (Sambrook et al., 1989), and following the appropriate manufacturer's instructions. Restriction and other enzymes were purchased from Takara Co., Ltd., Japan. Oligonucleotide primers were synthesized by Life Technologies Inc., USA. PCR amplification was achieved using Gene AmpPCR System 2400, Perkin-Elmer. The amplification was performed in $50 \mu \mathrm{L}$ containing $1.5 \mathrm{mM}$ $\mathrm{MgCl}_{2}, 0.5 \mathrm{nM}$ dNTPs (adenine, guanine, cytosine, and thymine), $20 \mathrm{pM}$ of each primer, 2.5 units of Taq DNA polymerase and $100 \mathrm{ng}$ of template DNA. A total of 30 cycles were run as follows: denaturation at $94^{\circ} \mathrm{C}$ for $30 \mathrm{~s}$, annealing at appropriate temperature for $1 \mathrm{~min}$ and extension at $72^{\circ} \mathrm{C}$ for $1.5 \mathrm{~min}$, followed by 1 cycle at $72^{\circ} \mathrm{C}$ for $5 \mathrm{~min}$.

\section{Construction of shuttle vectors expressing GFP}

Four GFP vectors were constructed in this study. A broad-host range plasmid of pME4510 served as a shuttle cloning vector and gfp cDNA was isolated from
pGFPuv. The first plasmid construct was pSKL01 in which lac promoter was used to drive expression of GFP. The promoter and gfp gene were isolated by $\mathrm{PCR}$ at an annealing temperature of $58^{\circ} \mathrm{C}$ from pGFPuv, using two primers with the following sequences: 5 'GGCGGAATTCATTAATGCAGCTG-3' and 5'-AGTTGGAATTCATTATTTGT-3'. Both of primers contained an EcoRI restriction site (underlined). The 988 bp of PCR product was then ligated into pME4510 linearized with EcoRI. The second plasmid construct was a promoterless, pSKP02. It was constructed by restriction of pME4510 with EcoRI and HindIII and ligated into $750 \mathrm{bp}$ fragment encoding the promoterless GFP isolated from pGFPuv by cutting with EcoRI and HindIII. From this plasmid, we constructed two other vectors, namely pSKT03 and pSKN04 in which tac and npt2 promoter drove the expression of GFP, respectively. The pSKP02 was linearized with Hindll and Xbal. PCR product carrying the tac promoter fragment was amplified from pMBB66EH at an annealing temperature of $58^{\circ} \mathrm{C}$ using primers $5^{\prime}$-ATAAAGCTTCTGGCAAATATTCTGAAA-3' and 5'CCTTCTAGAAATTGTTATCCGCTCACA-3'. The npt2 promoter was amplified from Tn5Mob at an annealing temperature of $60^{\circ} \mathrm{C}$, using primers 5'-CTCAAGCTTGCAGGTAGCTTGCAGTGGG-3' and 5'-CTCTCTAGAGCGCCATCAGATCCTTGGCG-3'. The first and second primers of both pairs contained a Hindll site and a $X$ bal site (underlined). The PCR products were cut with Hindll and $X b a l$ and ligated to the vector.

\section{Cells transformations}

All plasmid vectors were transformed into $E$. coli JM109 using a standard heat-shock transformation (Sambrook et al., 1989) and were electroporated into $P$. plecoglossicida using method as described by Bloemberg et al. (1997).

\section{GFP fluorescence}

The expression of GFP-expressing cells was

Table 1. Strains and plasmids used in this study

\begin{tabular}{|c|c|c|}
\hline $\begin{array}{l}\text { Bacterial strains or } \\
\text { plasmids }\end{array}$ & Description & Reference/source \\
\hline $\begin{array}{l}\text { Strain } \\
\text { E. coli } \mathrm{M} 109 \\
\text { P. plecoglossicida FPC } 951^{\top}\end{array}$ & $\begin{array}{l}\text { competent cell } \\
\text { wild type }\end{array}$ & $\begin{array}{l}\text { Takara } \\
\text { Nishimori et al. (2000) }\end{array}$ \\
\hline $\begin{array}{l}\text { Plasmid } \\
\text { pGFPuv } \\
\text { pME4510 } \\
\text { pMMB66EH } \\
\text { pSUP5011 } \\
\text { pSKP02 } \\
\text { pSKL01 } \\
\text { pSKT03 } \\
\text { pSKN04 }\end{array}$ & $\begin{array}{l}\mathrm{Amp}^{\mathrm{R}}, \mathrm{P}_{\text {lac }}, \text { gfp }^{+} \\
\mathrm{Gm}^{\mathrm{R}}, \text { promoterless } \\
\mathrm{P}_{\text {tac }}, \text { Amp } \\
\text { Tn5-Mob } \\
\mathrm{Gm}^{\mathrm{R}}, \text { promoterless, gfp } \\
\mathrm{Gm}^{\mathrm{R}}, \mathrm{P}_{\text {lac }}, \text { gfp }^{+} \\
\mathrm{Gm}^{\mathrm{R}}, \mathrm{P}_{\text {tac }}, \mathrm{gfp}^{+} \\
\mathrm{Gm}^{\mathrm{R}}, \mathrm{P}_{\text {npt2 }}, \mathrm{gfp}^{+}\end{array}$ & $\begin{array}{l}\text { Clontech } \\
\text { Rist and Kertesz (1998) } \\
\text { ATCC } 37620 \\
\text { Simon (1984) } \\
\text { this work } \\
\text { this work } \\
\text { this work } \\
\text { this work }\end{array}$ \\
\hline
\end{tabular}


assessed by eye using a UV transillumination (Vilber Lourmat, France) and fluorescence microscope (Olympus SZX-12, Japan) fitted with GFP filter set to examine colonies, and an Olympus BX-60 microscope to examine cells. The amount of fluorescence emitted by cultures was also assayed using a F-2000 fluorescence spectrophotometer (Hitachi, Japan) set to excite the cells at $395 \mathrm{~nm}$ and detect emission at $509 \mathrm{~nm}$. Culture was grown in LB medium with the antibiotic overnight and diluted to $A_{480}$ of 1.4 in the fresh LB medium. The cells were washed twice and diluted in the same volume of PBS, and the fluorescence was measured immediately.

\section{Growth of cells and plasmid stability}

$P$. plecoglossicida carrying the appropriate GFP. plasmid constructs were grown overnight in the presence of antibiotic LB broth. The cells were washed twice and diluted $1: 1000$ in LB broth without antibiotics, and growth of the cells was determined hourly at $A_{480}$. For plasmid stability assay, sequential propagation under non-selective conditions were performed by inoculating with $1: 1000(\mathrm{v} / \mathrm{v})$ of the previous culture daily. The bacterial culture was sampled daily to assess plasmid survival by comparing duplicate colony counts on selective and non-selective plates.

\section{Infectivity of fluorescent $\mathrm{P}$. plecoglossicida to ayu}

Two groups of fish were immersed for $15 \mathrm{~min}$ in $10^{7}$ CFU/mL of fluorescent $P$. plecoglossicida (pSKT03) and $P$. plecoglossicida (wild type), respectively. A control group was immersed in PBS. Kidney samples from dead fish were inoculated on LB plate with or without antibiotic. Pieces of tissue were immediately mounted in Tissue-Tek OTC Compound (Sakura, Japan), frozen in liquid nitrogen and then cut into $7 \mu \mathrm{M}$ sections on a cryostat (Sakura, Japan).

\section{Adherence of fluorescent $P$. plecoglossicida to ayu}

Fluorescent $P$. plecoglossicida FPC $951^{\top}$ (pSKT03), fluorescent $E$. coli JM109 (pSKL01), and one-micron fluoresbrite ${ }^{\mathrm{TM}}$ bright blue (BB) carboxylated microspheres (Polyscience, Inc., USA) were used. The bacterial cells and microspheres were suspended in PBS at $10^{7} \mathrm{CFU} / \mathrm{mL}$ and $10^{6}$ particles $/ \mathrm{mL}$, respectively. A mixture of bacteria and microspheres was made by adding an equal volume of the microspheres suspension to the bacterial suspension.

Seven different immersion experiments were performed as follows. In the experiments nos. 1, 2 and 3, fish were immersed in the fluorescent microsphere, fluorescent $E$. coli, and fluorescent $P$. plecoglossicida suspensions, respectively for $15 \mathrm{~min}$ and then dipped in $1 \mathrm{~L}$ of a $0.05 \%$ trypan blue (TB) solution for $10 \mathrm{~min}$. In the experiments nos. 4, 5 and 6, fish were immersed in the mixture of fluorescent microspheres and fluorescent $E$. coli, the mixture of fluorescent microspheres and fluores- cent $P$. plecoglossicida, and the mixture of fluorescent microspheres and $P$. plecoglossicida (wild type), respectively. In the experiment no. 7 , fish were immersed in fluorescent $P$. plecoglossicida suspension only. The fish were killed by a lethal dose of anesthetic (2-phenoxyethanol) and fixed in a $4 \%$ paraformaldehyde for $1 \mathrm{~d}$. The skin of the body surface was peeled off, and the fins were cut off from individuals. These tissues were mounted on glass slides with slow fade light antifade kit (Molecular probes, USA). All specimens were observed in detail under a fluorescence microscope.

\section{Results}

\section{Construction of plasmids}

We successfully developed GFP vectors for use in $P$. plecoglossicida (Fig. 1). The GFP vector, pSKL01 (Fig. 1A), was constructed in which lac promoter drove the expression of GFP. When PSKL01 was introduced into $P$. plecoglossicida, this resulted in weak green fluorescence of GFP which could still be observed under a fluorescence microscope (Fig. 2A). Thus, to intensify fluorescence, other constructs were prepared in which other promoters were used to express GFP. First, we constructed the promoterless GFP vector, designated pSKP02 (Fig. 1D), by cloning promoterless GFP fragments from pGFPuv to the pME4510. When pSKP02 was introduced into $P$. plecoglossicida, no fluorescence could be observed (Fig. 2D). However, when tac promoter was cloned in the upstream of gfp gene, yielding pSKT03, and introduced into $P$. plecoglossicida, the resulting fluorescence of the transformants was stronger (Figs. 1B and 2B). Identical approach was used in which pSKNO4 with npt2 promoter was used to drive GFP expression (Figs. $1 \mathrm{C}$ and $2 \mathrm{C}$ ).

\section{GFP expression}

Expression of GFP in P. plecoglossicida was demonstrated by fluorescence microscopy of individual cells with all the constructs, as shown in Fig. 2. When fluorescence was measured by fluorometry, the emission were as follows: $4,14,5$, and 1 fluorescent units, for $P$. plecoglossicida carrying pSKL01, pSKT03, pSKN04, and wild type, respectively. The emission of $980,53,826$, and 2 fluorescent units were for $E$. coli carrying pSKL01, pSKT03, pSKN04, and wild type, respectively. All GFP constructs lead much more fluorescence in $E$. coli than P. plecoglossicida.

\section{Plasmid stability}

Colonies grown on the present antibiotic media gave uniform fluorescence, but those grown on media not containing antibiotic showed fluorescent and nonfluorescent colonies that indicated plasmid loss. The stability of the GFP-plasmid constructs were investigated 


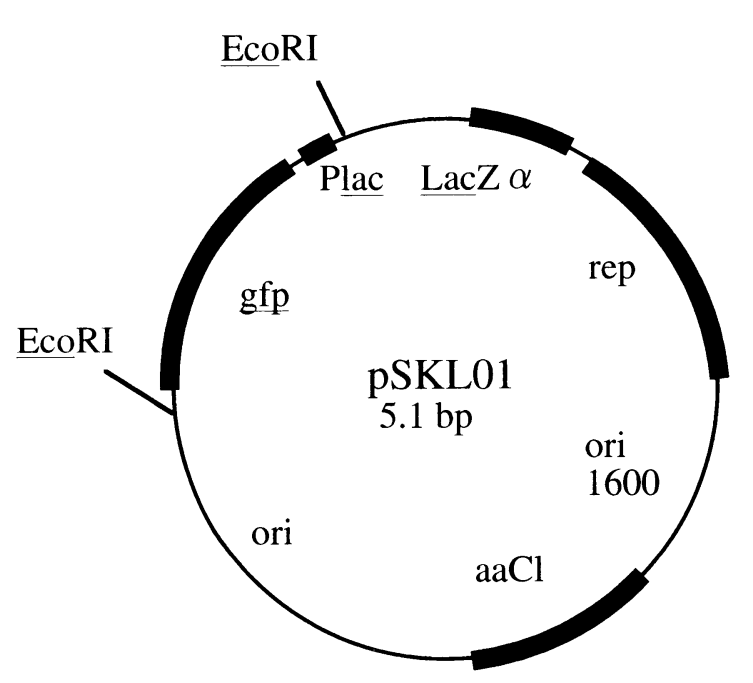

(A)

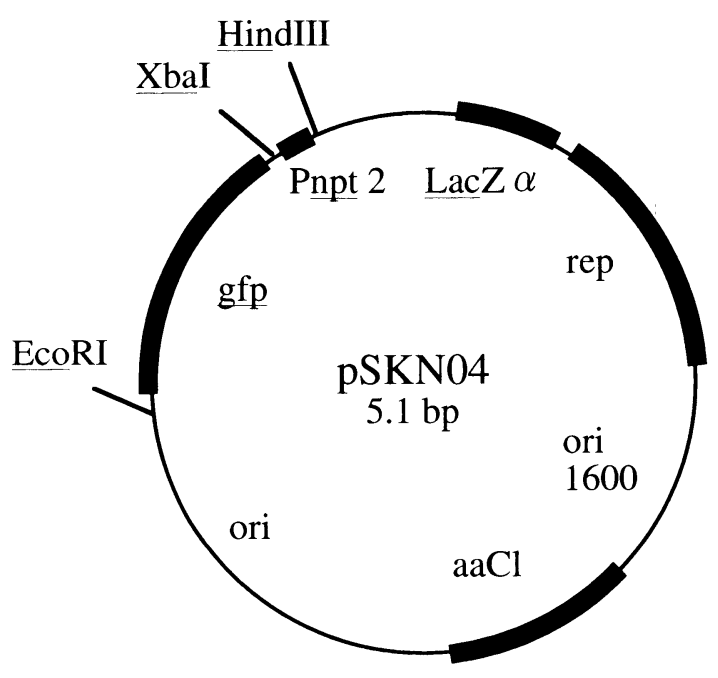

(C)

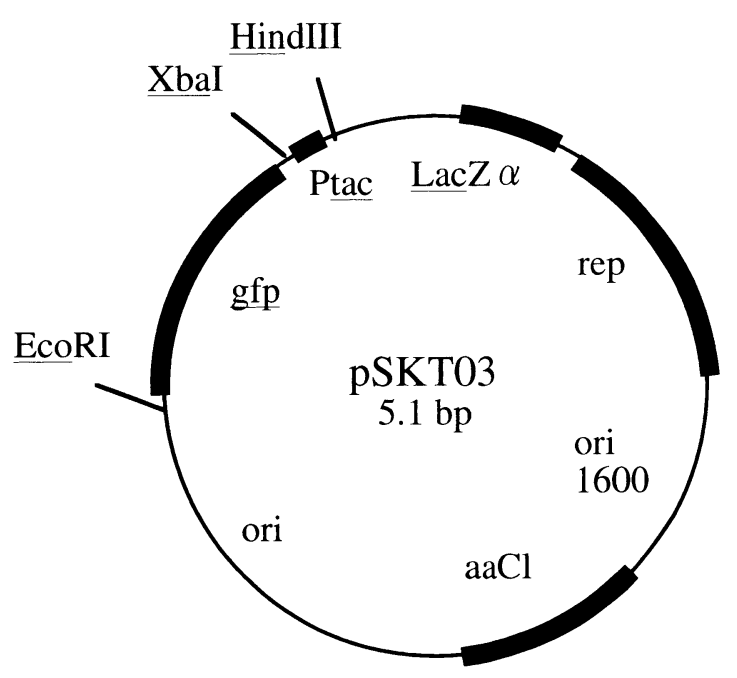

(B)

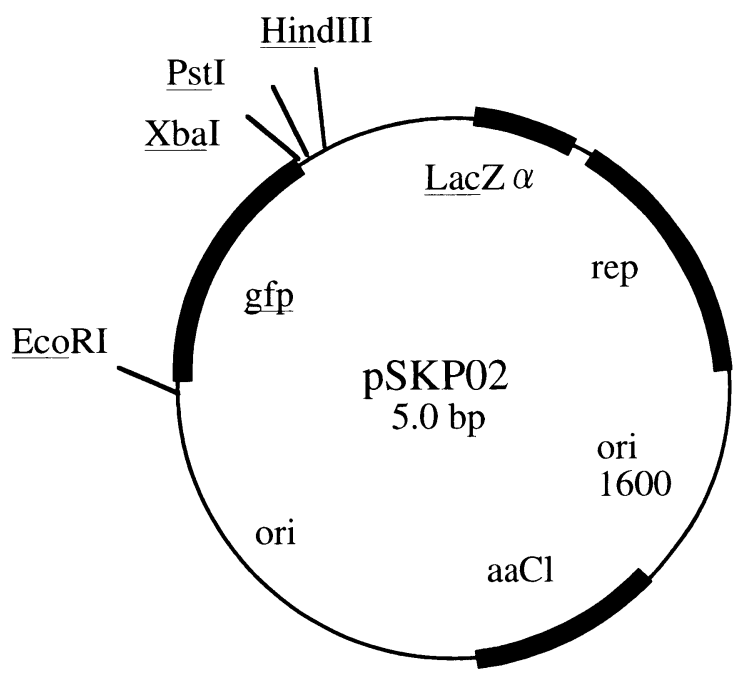

(D)

Fig. 1. Structure of the GFP vectors, constructed as described in Materials and Methods, containing either lac (A), tac (B), npt2 (C) promoters, and promoterless (D). Promoter and gfp genes are indicated with specific restrictions. Plasmids are not shown to scale.

during sequential propagation in the absence of antibiotic selection, and show that after subculturing and growth for 4 successive days, the cells, ranging from $25 \%$ (pSKL01) up to 70\% (pSKT03) and 72\% (pSKN04), still carried their respective plasmid (Fig. 3). However, the relative highly instability of plasmid pSKL01 under nonselective condition suggests that this plasmid may not be suitable for long-term experiments without antibiotic pressure.

\section{Plasmid burden}

Such differences in the growth rate occurred because of the metabolic load on the cells caused by the need to replicate the plasmid, and to express its gene, the growth of the cells in liquid LB medium, with and without GFP plasmid, was assayed. The results show that under laboratory conditions, the growth rate of $P$. plecoglossicida with or without the GFP expressing plasmid were identical (Fig. 4), indicating that there is no significant burden to the cells carrying these plasmids.

\section{Infectivity and adherence assays}

No mortalities or clinical signs of disease were observed in negative control fish. At day 10 post infection, cumulative mortalities in 10 experimentally infected fish reached $90 \%$ (pSKT03) and $80 \%$ (wild type). All diseased fish showed clinical signs and gross pathological features consistent with those described in fish with BHA (Wakabayashi et al., 1996). Fluorescent $P$. plecoglossicida (pSKT03) was also observed in the kid- 

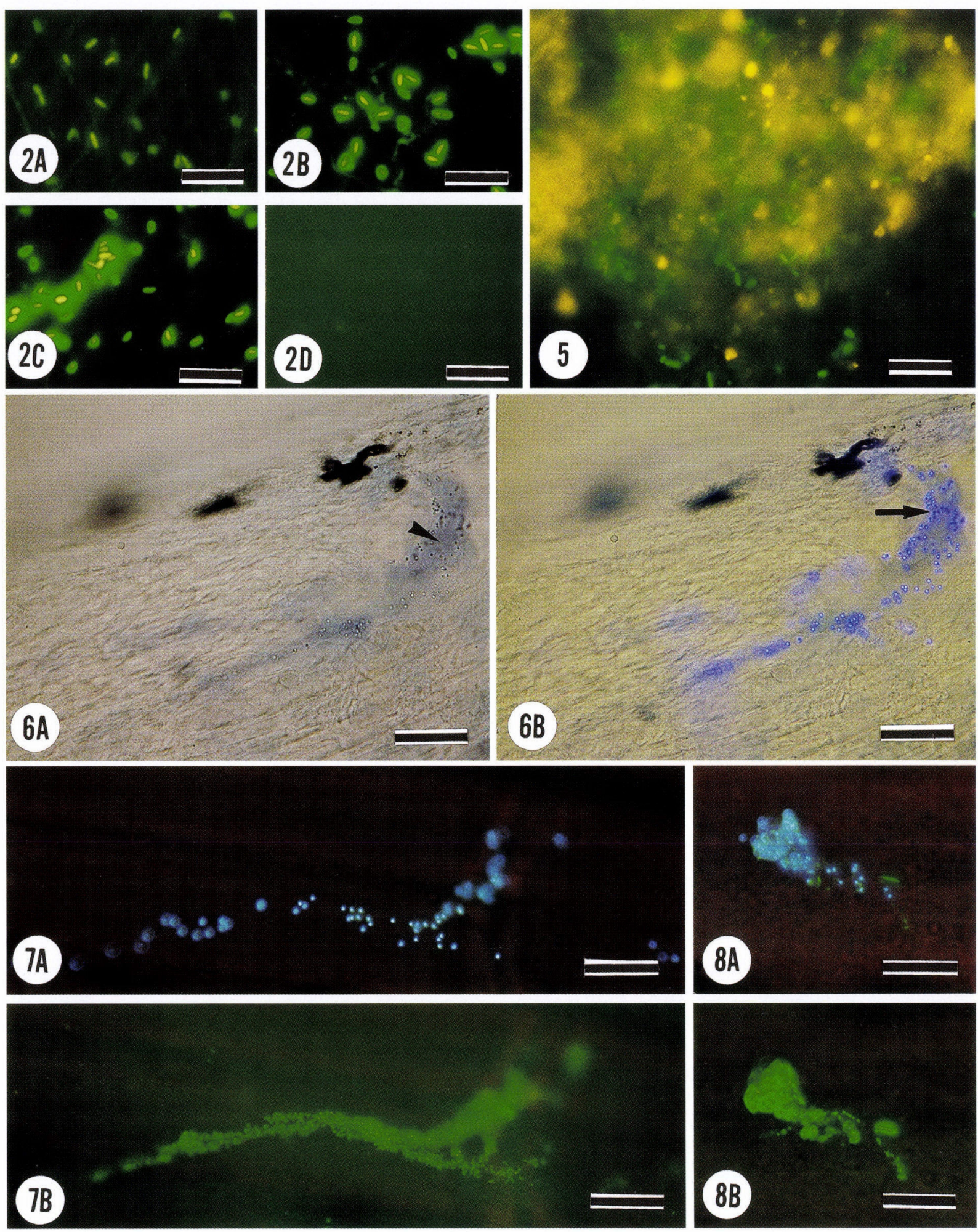

Figs. 2, 5-8. Light and fluorescence micrographs of GFP-expressing cells and microspheres.

2. Fluorescence micrographs of $P$. plecoglossicida carrying GFP constructs. (A) pSKL01 (lac promoter), (B) pSKT03 (taq promoter), (C) pSKN04 (npt2 promoter), and (D) pSKP02 (promoterless). 5. Cryostate section of kidney of ayu infected with fluorescent $P$. plecoglossicida showing numerous fluorescent bacteria. 6 . Fluorescent microspheres adhering to the body surface of ayu: (A) light microscopy, (B) fluorescence microscopy. Necrotic tissues stained with trypan blue (arrow head) and fluorescent microspheres (arrow) are shown. 7. Fluorescent microspheres and fluorescent $P$. plecoglossicida adhering to the body surface of ayu: (A) fluorescent microspheres, (B) fluorescent $P$. plecoglossicida. 8. Fluorescent microspheres and fluorescent $E$. coli adhering to the body surface of ayu: (A) fluorescent microspheres, (B) fluorescent $E$. coli. Scale bars for $2 \mathrm{~A}-2 \mathrm{D}$ and 5 are $10 \mu \mathrm{m}$, and $6 \mathrm{~A}-8 \mathrm{~B}$ are $30 \mu \mathrm{m}$. 


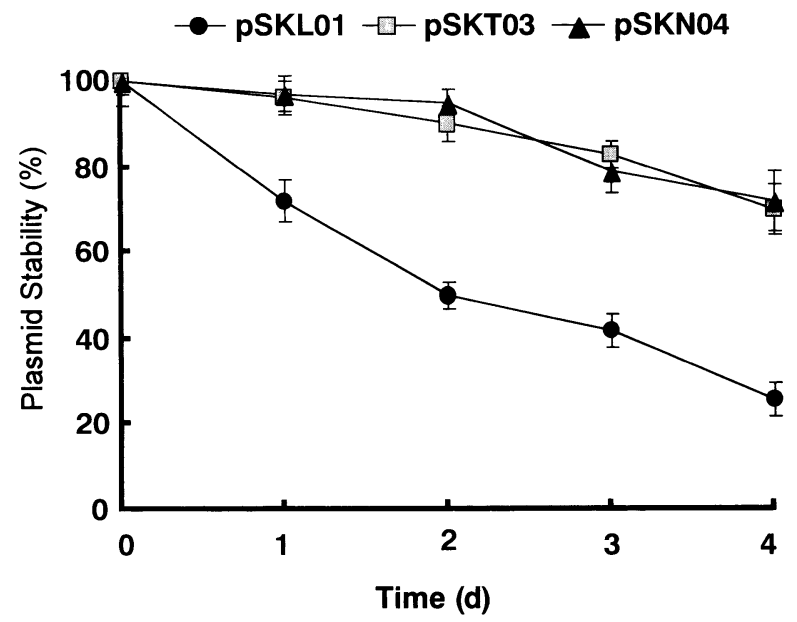

Fig. 3. Stability of plasmids in P. plecoglossicida under nonselective conditions.

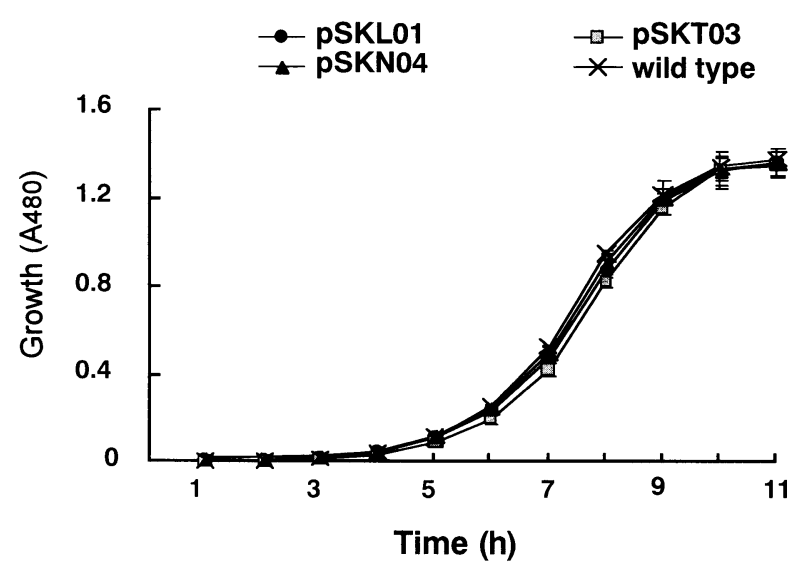

Fig. 4. Growth of $P$. plecoglossicida with or without GFP plasmids.

ney cryosection of dead fish infected by this strain (Fig. $5)$.

The fluorescent microspheres in the skin and fins were distributed patchly and were almost always located in the area in which the tissues were stained with trypan blue (Fig. 6). In contrast, significant loss of fluorescence of bacteria occurred in fish immersed in trypan blue. Consequently, fluorescent bacterial cells could hardly be observed under a fluorescence microscope. For these reasons, we used fluorescent microspheres instead of trypan blue for detecting microscopic injuries in the body surface of fish. A single cell as well as assemblages of fluorescent $P$. plecoglossicida were observed in the area in which fluorescent microspheres were present (Fig. 7). Similar results were also found in the fish immersed with fluorescent $E$. coli (Fig. 8). We found no fluorescence in the skin or fins of fish infected with $P$. plecoglossicida (wild type).

\section{Discussion}

Green fluorescent protein cDNA has been expressed in a variety of both gram-positive and gramnegative bacteria (Lewis and Errington, 1996; Valdivia at al., 1996; Bloemberg et al., 1997). In the present study, we described the construction of new GFP-containing plasmids for use in $P$. plecoglossicida. Plasmids pSKL01, pSKT03 and pSKN04 carry a bright mutant of GFP (Crameri at al., 1996), which allowed easy detection with a standard fluorescence microscope. In the presence of the lac promoter, high expression of GFP were seen in E. coli, whereas a much weaker of induction was seen in $P$. plecoglossicida. This is consistent with previous observations that the lac promoter is expressed weakly in pseudomonads (Matthysse et al., 1996; Rist and Kertesz, 1998). When another construct was made in which the npt2 promoter was used to express GFP in pSKN04, intenser fluorescence was seen in P. plecoglossicida. The expression of GFP in $P$. plecoglossicida was the highest when taq promoter was used to drive GFP expression. This suggested that $P$. plecoglossicida carrying pSKT03 could be used for in vivo experiments using fish models. In addition, pSKT03 was relatively stable under non-selective pressure and there was no significant burden to the cell carrying this plasmid.

The advantages of using GFP as a marker include ease of detection, no requirement for exogenous substrate or energy source, and no processing of the cells (Chalfie et al., 1994; Kremer et al., 1995). Histological study confirmed the presence of fluorescent $P$. plecoglossicida (pSKT03) in fish infected with this strain. The conventional method using indirect antibody labeling needs longer processing times for bacterial detection. Using the GFP markers, bacteria in cryostate sections were directly visualized without any immunological treatment. Moreover, by tracking GFPexpressing bacteria in animal models, the distribution of bacteria in tissue and transmission pathway could be clarified (Ling et al., 2000)

In addition to the new research possibilities by using GFP as a reporter for $P$. plecoglossicida, we demonstrated the useful technical application of the plasmids to visualize the bacteria in the body surface of infected fish. As shown for the adherence assay in this study, the adherence of fluorescent $P$. plecoglossicida as well as $E$. coli on the body surface of ayu could be easily detected using fluorescence microscopy. The present study revealed that bacteria adhered predominantly in the area where microspheres were found. Kiryu and Wakabayashi (1999) demonstrated that microspheres adhered predominantly to the surface of microscopic injuries that were stained with trypan blue. However, since the fluorescence of bacteria disappeared when stained with trypan blue, we used fluorescent micro- 
spheres indirectly to specify microscopic injuries. Since the fluorescent $P$. plecoglossicida as well as $E$. coli were almost always located in the area where the fluorescent microspheres were also present, we concluded that the injuries were the main site of bacterial adherence to the skin and fins of fish. However, pathogenic bacteria need to survive at adhesion sites and to escape from the host defense system. These processes seem to decide the fate of $P$. plecoglossicida and $E$. coli in the microscopic injuries. Further studies on the mechanism of invasion of the adhered bacteria into the host tissues are needed.

Several new variants of the GFP have recently become commercially available. pBFP2 (Clontech) is a mutant expressing blue fluorescence. Another recently available one is a red-shift excitations variant (pEGFP). The availability of these variants will significantly extend the usefulness of GFPs in bacteria and will enable us to compare the ability of different strain and species to infect fish in co-infection experiments. For example, the expression of the gfp gene in $P$. plecoglossicida and blue-fluorescent variant in other fish pathogenic bacteria such as Flavobacterium psychrophilum, which also causes another serious disease of ayu, would allow a comparison of the infection kinetics of the two different species in co-infection experiments using ayu as a model animal. Moreover, with the help of these, it should be possible to visualize gene regulation events, in bacteria, in cell culture and in the host, to identify specific adaptation mechanisms and improve understanding of host-pathogen interactions that make persistent infection possible (Josenhans et al., 1998).

\section{Acknowledgements}

We are indebted to Dr. Michael A. Kertesz, Institute of Microbiology, Swiss Federal Institute of Technology Zurich, for the gift of plasmid pME4510 and to Dr. I. Hirono, Tokyo University of Fisheries, for suggesting the design of GFP vectors. We thank Nisshin Marine Tech Co., Ltd., for providing ayu and also Dr. Craig J. Hayward, Chungbuk University, for reviewing the manuscript.

\section{References}

Bloemberg, G. V., G. A. O'toole, B. J. J. Lugtenberg and R. Kolter (1997): Green fluorescent protein as a marker for Pseudomonas spp. Appl. Environ. Microbiol., 63, 45434551.

Chalfie, M., Y. Tu, G. Eukirchen, W. W. Ward and D. C. Prasher (1994): Green fluorescent protein as marker of gene expression. Science, 263, 802-805.

Crameri, A., E. A. Whitehorn, E. Tate and P. C. Stemmer (1996): Improved green fluorescent protein by molecular evolution using DNA shuffling. Nature Biotech. 14, 315319.

Crouse-Eisnor, R. A., D. K. Cone and P. H. Odense (1985):
Studies on relations of bacteria with skin surface of Carrassius auratus L. and Poecilia reticula. J. Fish Biol., 27, 395-402.

Josenhans, C., S. Friedrich and S. Suerbaum (1998): Green fluorescent protein as a novel reporter system in Helicobacter sp. FEMS Microbiol. Lett., 161, 263-273.

Kremer, L. A. Baulard, J. Estaquier, O. Poulain-Godefroy and C. Locht (1995): Green fluorescent protein as a new expression marker in mycobacteria. Mol. Microbiol., 17, 913922.

Kiryu, I. and H. Wakabayashi (1999): Adherence of suspended particles to the body surface of rainbow trout. Fish Pathol., 34, 177-182.

Lewis, P.J. and J. Errington (1996): Use of green fluorescent protein for detection of cell-specific gene expression and subcellular protein localization during sporulation in Bacillus subtilis. Microbiol., 142, 733-740.

Ling, S. H. M., X. H. Wang, L. Xie, T. M. Lim and K.Y. Leung (2000): Use of green fluorescent protein (GFP) to study invasion pathway of Edwardsiella tarda in in vivo and in vitro fish models. Microbiol., 146, 7-19.

Matthysse, A. G., S. Stretton, C. Dandie, N. McClure and A. Goodman (1996): Construction of GFP vectors for use in Gram-negative bacteria other than Escherichia coli. FEMS Microbiol. Lett., 145, 87-94.

Nishimori, E., K. Kita-Tsukamoto and H. Wakabayashi (2000). Pseudomonas plecoglossicida sp. nov., the causative agent of bacterial hemorrhagic ascites of ayu, Plecoglossus altivelis. Int. J. Syst. Evol. Microbiol., 50, 83-89.

Rist, M. and M. A. Kertesz (1998): Construction of improved plasmid vectors for promoter characterization in Pseudomonas aeruginosa and other Gram-negative bacteria. FEMS Microbiol. Lett., 169, 179-183.

Sambrook, J., E. F. Fritsch and T. Maniatis (1989): Molecular Cloning: a Laboratory Manual, $2^{\text {nd }}$ ed. Cold Spring Harbor Laboratory Press. Cold Spring Harbor, New York, section 1.

Schneider, R. and B. L. Nicholson (1980): Bacteria associated with fin rot diseases in hatchery reared Atlantic salmon (Salmo salar). Can. J. Fish. Aquat. Sci., 37, 1505-1513.

Simon, R. (1984): High frequency mobilization of gram-negative bacteria replicon by the in vitro constructed Tn5-Mob transposon. Mol. Gen. Genet., 196, 413-420.

Speare, D. J. and S. M. Mirsalimi (1992): Pathology of the mucous coat of trout skin during an erosive bacterial dermatitis: a technical advance in mucous coat stabilization for ultrastructural examination. J. Comp. Pathol., 106, 201211.

Sukenda and H. Wakabayashi (1999): Immersion immunization of ayu (Plecoglossus altivelis) with Pseudomonas plecoglossicida bacterin. Fish Pathol., 34, 163-164.

Sukenda and H. Wakabayashi (2000): Tissue distribution of Pseudomonas plecoglossicida in experimentally infected ayu (Plecoglossus altivelis) studied with real-time quantitative PCR. Fish Pathol., 35, 223-228.

Valdivia, R. H., A. E., Hromochkyj, D. Monack, L. Ramakrishnan and S. Falkow (1996): Application for gene fluorescent protein (GFP) in the study of host-pathogen interactions. Gene, 173, 47-52.

Ventura, M. T. and J. M. Grizzle (1987): Evaluation of portals of entry of Aeromonas hydrophila in channel catfish. Aquaculture, 65, 205-214.

Wakabayashi, H., K. Sawada, K. Ninomiya and E. Nishimori (1996): Bacterial hemorrhagic ascites of ayu caused by Pseudomonas sp., Fish Pathol., 31, 239-240. (In Japanese with English summary) 